\title{
Rancang Bangun Aplikasi E-Commerce Dengan Pemanfaatan Teknologi Mobile Computing Sebagai Akselerator Usaha Mikro Kecil Menengah (Umkm) Di Kabupaten Malang
}

\author{
Alexius Endy Budianto, S.Kom, MM.; Amak Yunus, M.Kom \\ Fakultas Teknologi Informasi Universitas Kanjuruhan Malang
}

\begin{abstract}
E-Commerce Application design by the Use of Mobile Computing Technology as Accelerator for Micro, Small Medium Enterprises (UMKM) in Malang.

Advances in information technology contribute positively to the company's operations. UMKM sector company engaged an area of business that needs to make use of IT in delivering services to customers. ECommerce Applications design by the Use of Mobile Computing Technology as Accelerator for Micro, Small Medium Enterprises (UMKM) that can achieve. It's performance, organizational culture, business resources and information technology in accordance with company requirements. It takes a strong commitment from management UMKM sector.
\end{abstract}

Keywords: Mobile Computing, UMKM, Information Technology, IT Performance, Business e-Commerce

\section{Pendahuluan}

Perkembangan teknologi dan komunikasi membawa dampak bagi kehidupan manusia saat ini. Hal ini tampak pada adanya perubahan-perubahan dalam kehidupan sehari-hari seseorang yang tidak terlepas dari pembelian kebutuhan barang dan jasa, baik dalam jumlah besar atau sekedar memenuhi kebutuhan pada saat ini dengan cara yang sangat mudah dan membutuhkan waktu yang relatif singkat. Misalnya saja saat ini pembelian atau pemasaran suatu produk bisa dilakukan melalui media internet. Seiring dengan perubahan tersebut, perusahaan harus membuat produk yang lebih baik dari produk saingannya dan membuatnya lebih menarik bagi konsumen, baik perubahan pada produk/usaha ataupun pada harga, promosi serta aspek pemasaran lain yang menimbulkan permintaan konsumen. Berlakunya sistem perekonomian bebas yang mengglobal makin dirasakan oleh para pelaku ekonomi persaingan antar perusahaan sejenis semakin bertambah ketat disamping perubahan lingkungan bisnis yang bertindak sangat dinamis.

Hal tersebut membawa dampak bagi kelangsungan hidup sebuah perusahaan. Perusahaan dalam melakukan usahanya selalu bertujuan untuk mendapatkan keuntungan yang optimal, dan untuk memenuhinya maka perusahaan perlu memberikan pelayanan-pelayanan yang mampu memberikan kepuasan terhadap konsumen. Perusahaan dalam mempromosikan usahanya dituntut untuk meningkatkan kualitas dan kuantitasnya, terutama saat ini dengan mudah ditemui situs web yang banyak sekali menampilkan promo tempat usahanya. Hal ini harus diikuti oleh sebuah perusahaan apabila ingin usahanya bisa berkembang dengan baik dan tentunya bisa terus berkembang bila Unit Usaha tersebut kita bisa memperbaiki sistem pemasarannya. Keberadaan usaha Mikro Kecil Menengah (UMKM) memiliki peranan penting dalam mewujudkan pertumbuhan ekonomi dan industri suatu negara.

Di Kabupaten Malang pertumbuhan ekonomi diperoleh dari kontribusi UMKM. Selain memberikan kontribusi pada pendapatan daerah juga memberikan kontribusi pada peluang kerja. Dimana UMKM dapat menyerap tenaga kerja yang cukup banyak. Kondisi pekonomian secara global, mengharuskan UMKM untuk melakukan perubahan secara komprehensif guna meningkatkan daya saingnya.

Salah satu faktor penting yang akan menentukan daya saing UMKM adalah penerapan teknologi informasi (TI). Penggunaan TI sesuai kebutuhan dapat meningkatkan transformasi bisnis melalui kecepatan, ketepatan dan efisiensi pertukaran informasi dalam jumlah yang besar maupun peningkatan pelayanan kepada pelanggan. UMKM dikatakan memiliki daya saing global apabila mampu menjalankan operasi bisnisnya secara reliable, mobile, seimbang, dan berstandar tinggi. Bharadwaj et al.,( 1993,p83-84) menjelaskan bahwa keunggulan bersaing merupakan hasil dari implementasi strategi yang memanfaatkan berbagai sumber daya yang dimiliki perusahaan.

Dalam rangka menciptakan keunggulan kompetitif yang berkelanjutan melalui teknologi informasi, maka dapat dirumuskan sebagai berikut:

1) Aplikasi E-Commerce dengan Teknologi Mobile Computing ini mempengaruhi bisnis dan kinerja organisasi. Untuk menentukan peluang bisnis atas dasar TI.

2) Untuk menilai inovasi teknologi.

3) Untuk merancang teknologi baru dalam bentuk model bisnis. 
4) Untuk mengelola perubahan yang berkaitan dengan teknologi.

5) Untuk menerapkan teknologi tepat guna.

Peran dan pengaruh Aplikasi E-Commerce dengan Teknologi Mobile Computing ini dalam menciptakan keunggulan kompetitif dalam UMKM akan dibahas dari dua pendekatan yang berbeda:

1) Pendekatan Berbasis Pasar : Dalam pendekatan ini, diyakini bahwa kelangsungan hidup suatu organisasi tergantung pada pasar, kebutuhan pelanggan dan menciptakan nilai bagi pelanggan. Sebuah organisasi secara optimal harus menyediakan pelanggan dengan kebutuhan mereka di waktu yang tepat dan menempatkan dan menciptakan keunggulan kompetitif yang berkelanjutan untuk dirinya sendiri melalui dihitung pelaksanaan alat teknologi informasi (Mobile Computing).

2) Pendekatan Berbasis Sumber Daya : Dalam pendekatan ini, diyakini bahwa kebutuhan organisasi untuk mengenali sumber daya, kemampuan dan keterampilan dan kemudian, mengidentifikasi kebutuhan pelanggan yang dapat diberikan secara efisien menggunakan sumber daya dan keterampilan. Salah satu sumber daya organisasi yang paling penting dan keterampilan adalah teknologi informasi yang dapat menjadi sumber keunggulan kompetitif yang berkelanjutan.

\section{Pengertian E-COMMERCE}

Electronic Commerce (Perniagaan Elektronik), sebagai bagian dari Electronic Business (bisnis yang dilakukan dengan menggunakan electronic transmission), oleh para ahli dan pelaku bisnis dicoba dirumuskan definisinya. Secara umum e-commerce dapat didefinisikan sebagai segala bentuk transaksi perdagangan/perniagaan barang atau jasa (trade of goods and service) dengan menggunakan media elektronik. Jelas, selain dari yang telah disebutkan di atas, bahwa kegiatan perniagaan tersebut merupakan bagian dari kegiatan bisnis. Kesimpulannya, "e-commerce is a part of e- business".

Media elektronik yang dibicarakan di dalam tulisan ini untuk sementara hanya difokuskan dalam hal penggunaan media internet. Pasalnya, penggunaan internetlah yang saat ini paling populer digunakan oleh banyak orang, selain merupakan hal yang bisa dikategorikan sebagai hal yang sedang „booming $\square$. Perlu digarisbawahi, dengan adanya perkembangan teknologi di masa mendatang, terbuka kemungkinan adanya penggunaan media jaringan lain selain internet dalam e-commerce.

\section{Mobile Computing}

Seiring dengan berkembenbangnya teknologi informasi yang sangat pesat sehingga terciptalah teknologi yang sangan inovatif dimana koninukasi jaringan lebih mudah dan portable sehingga tidak membutuhkan tempat khusus untuk menampatkannya, salah satunya adalah handphone sebuah device yang mudah kita kita bawa kemana- mana tanpa perlu membutuhkan kabel dan sangat mudah di bawa-bawa, cukup kita simpan di saku atau di tas kecil kita. Teknologi ini membantu kita untuk menyelesaikan masalah dan sekarang bisa memenuhi kebutuhan hidup kita di bidang informasi, teknologi ini erat kaitannya dengan proses komputasi yang menjadikannya bermanfaat dalam menyelesaikan masalah maupun pekerjaan.

Mobile computing adalah komunikasi jaringan tampa menggunakan kabel serta mudah dibawa atau berpindah tempat (Portable), tetapi berbeda dengan komputsi modern, contoh dari mobile computing ini adalah GPS, Smart Phone dan lain sebagainnya.

\section{Konsep Data dan Informasi}

Secara konseptual data dan informasi mempunyai arti yang berbeda. Data merupakan kata jamak dari datum yang berarti gambaran mengenai fakta, statistik, dan lain sebagainya, yang belum memiliki makna atau arti, Sedangkan informasi didefinisikan sebagai kumpulan dari fakta, statistik dan lain-lain yang memiliki makna atau arti. Jadi yang membedakan data dan informasi adalah makna yang dikandungnya. Oleh karena itu tidak heran jika pemakaian kata data dan informasi sering kali dipertukarkan.

Untuk lebih memperjelas perbedaan data dan informasi, maka dibawah ini dijelaskan definisi yang diberikan oleh Burch Jhon G. Jr. dalam bukunya yang berjudul "Information Systems : Theory and Practice " : Data adalah fakta dasar, data baru berarti jika sudah diolah dan dikaitkan dengan konteks tertentu. Informasi adalah suatu hasil pengolahan data dalam bentuk agregat untuk menghasilkan pengetahuan atau kemampuan.

Secara skematis proses pengolahan data menjadi informasi dapat dijelaskan pada gambar 1 dibawah ini : 


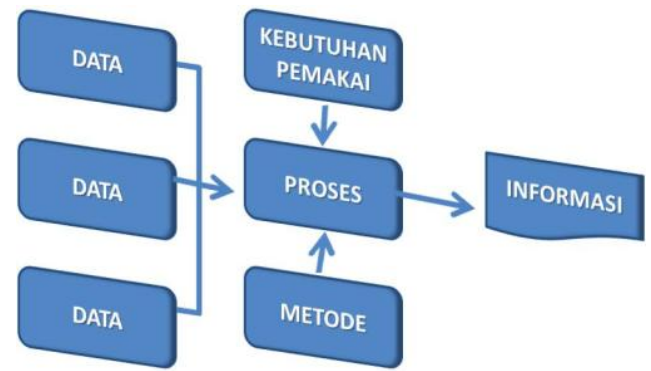

Garnbar 1. Transforrnasi Data Menjadi Inforrnasi

\section{Tahapan Dalam Pembentukan Sistem}

Setiap subsistem dari organisme hidup-lahir, bertumbuh menjadi matang, berfungsi dan akhimya mati. Proses evolusioner ini disebut siklus kehidupan sistem atau sistem development life cycle (SDLC). Menurut Raymond McLeod proses pengembangan sistem mencakup 5 (lima) tahapan, yaitu :

1. Tahap Perencanaan.

Dalam tahap perencanaan merupakan tahapan awal yang dilakukan dalam proses perancangan suatu sistem. Pada tahap ini kegiatan yang dilakukan antara lain adalah : Menyadari masalah, mendefinisikan masalah, menentukan tujuan sistem, mengidentifikasi kendala-kendala sistem, membuat studi kelayakan, mempersiapkan usulan penelitian sistem, menyetujui atau menolak penelitian proyek, menetapkan mekanisme pengendalian.

2. Tahap Analisis.

Pada saat perencanaan telah selesai, tahap selanjutnya beralih pada analisis dari sistem yang telah ada. Analisis sistem adalah penelitian atas sistem yang telah ada dengan tujuan untuk merencanakan sistem yang baru atau diperbarui. Pada tahap ini kegiatan yang dilakukan adalah : Mengumumkan penelitian sistem, mengorganisasikan tim proyek, mendefinisikan kebutuhan informasi, mendefinisikan kriteria kinerja sistem, menyiapkan usulan rancangan, menyetujui atau menolak rancangan proyek.

3. Tahap Rancangan.

Dengan memahami sistem yang ada dan persyaratan-persyaratan sistem baru, kemudian beralih pada tahap memvahas rancangan sistem baru. Rancangan system adalah penentuan proses dan data yang diperlukan oleh sistem baru. Ini biasanya digunakan suatu alat bantu untuk menggambarkan rancangan sistem yang akan dibuat. Alat bantu tersebut biasanya adalah Data Flow Diagram kegiatan yang dikerjakan pada tahap ini antara lain adalah : Menyiapkan rancangan sistem yang terinci, mengidentifikasikan berbagai altematif konfigurasi sistem, mengevaluasi berbagai altematif konfigurasi sistem, memilih konfigurasi yang terbaik, menyiapkan usulan penerapan, menyetujui atau menolak penerapan sistem.

4. Tahap Implementasi.

Dalam tahap implementasi kegiatan memperoleh dan mengintegrasikan sumber daya fisik dan konseptual yang menghasilkan suatu sistem yang bekerja. Dalam kegiatan ini ada 8 (delapan) tahapan kegiatan yaitu : Merencanakan penerapan, mengumumkan penerapan, mendapatka sumber daya perangkat keras, mendapatkan sumber daya perangkat lunak, menyiapkan database, menyiapkan fasilitas fisik, mendidik peserta dan pemakai, masuk ke sistem yang baru.

5. Tahap Penggunaan.

Dalam tahapan ini mencakup 3 (tiga) kegiatan sekaligus, yaitu menggunakan sistem melakukan audit terhadap sistem yang bersangkutan dan melakukan perawatan terhadap sistem. Dalam menggunakan sistem, diharapkan pemakai menggunakan sistem sesuai dengan tujuan yang telah digariskan sebelumnya. Sedangkan pada kegiatan mengaudit sistem, dilakukan studi untuk mengetahui sampai sejauh mana sistem yang bersangkutan dapat memenuhi kriteria yang telah ditentukan sebelumnya. Kegiatan ini biasanya dilakukan berulang-ulang dengan periode tertentu. Pada kegiatan sistem selain dilakukan kegiatan yang berhubungan dengan perawatan sistem yang bersangkutan, juga dilakukan modifikasi agar system tetap dapat mendukung penyelesaian pekerjaan yang diperlukan. Hal tersebut dilakukan antara lain untuk :

a. Menjaga agar sistem selalu „Up-to-date $\square$ dan sesuai dengan pekerjaan.

b. Meningkatkan kinerja karena adanya saran-saran baru yang lebih baik.

c. Memperbaiki kesalahan-kesalahan yang ada.

\section{Tujuan Penelitian}

Tujuan yang diharapkan dapat dicapai dalam penelitian ini adalah sebagai berikut:

1) Rancang Bangun Aplikasi E-Commerce dengan Teknologi Mobile Computing untuk mengoptimalkan pelayanan serta perkembangan UMKM ke masyarakat Kabupaten Malang. 
2) Memberikan informasi tentang Pemanfaatan Teknologi Mobile Computing dalam Dunia Usaha khususnya UMKM.

3) Mengidentifikasi berbagai masalah yang berkaitan dengan Pemanfaatan Teknologi Mobile Computing Sebagai Akselerator Dunia Usaha dan solusinya

4) Mengembangkan kolaborasi antara berbagai pihak sebagai upaya untuk meningkatkan Pemanfaatan Teknologi Mobile Computing Sebagai Akselerator Dunia Usaha.

\section{Metode Penelitian}

Sesuai dengan latar belakang dan permasalahan yang terjadi serta solusi atas permasalahan yang ada peneliti menggunakan pengolahan data yang digunakan untuk mendukung hasil penelitian ini diperoleh melalui wawancara ( Interview ), Observasi dan dokumentasi dengan tujuan untuk merancang aplikasi e-Commerce dengan pemanfaatan teknologi mobile computing sebagai akselerator usaha mikro kecil menengah (UMKM) di Kabupaten Malang.

\section{Teknik pengumpulan data}

Teknik pengumpulan data yang digunakan untuk mendukung hasil penelitian ini diperoleh melalui wawancara ( Interview ), Observasi dan dokumentasi

\section{Analisa data}

Analisa data dilakukan melalui tabulasi data hasil pengumpulan data kemudian digunakan analisa komparasi untuk Rancang Bangun Aplikasi E-Commerce Dengan Pemanfaatan Teknologi Mobile Computing Sebagai Akselerator Usaha Mikro Kecil Menengah (UMKM) Di Kabupaten Malang

\section{Rancangan penelitian}

\section{HASIL YANG DICAPAI \\ Tujuan Uji Coba}

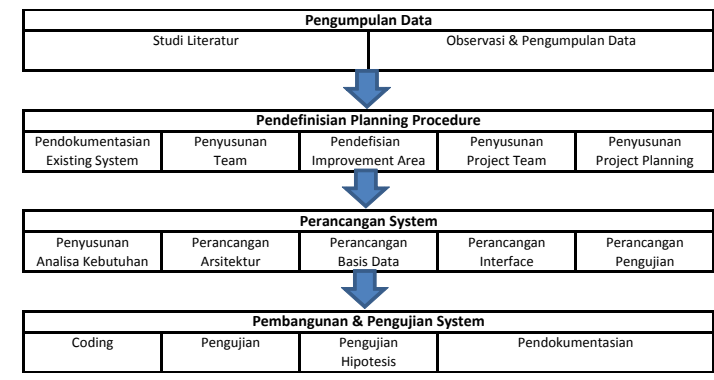

Gambar 2. Alur Metodologi Penelitian

Tujuan dilakukannya uji coba adalah untuk menguji modul proses-proses penting dalam website sistem informasi penjualan kerajinan agar dapat dipastikan sistem berjalan sesuai yang diharapkan saat diimplementasikan/digunakan. Pengujian Aplikasi UMKM Penjualan Online Galeri Al-Wafa menggunakan metode pengujian black box yang berfokus pada kebutuhan fungsional program

Langkah pengujian sistem dengan kode: Test Case (TC) - Kode use case diikuti nomor use case Nomor urut pengujian.

\section{Proses sistem katalisator rantai pasokan}

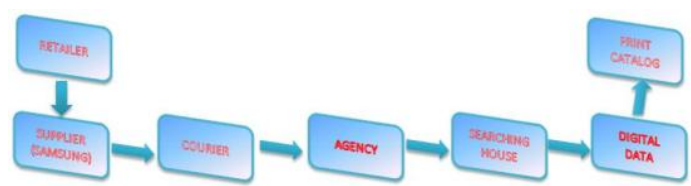

Konsep Orbis Group mengubah rantai pasokan linear menjadi $h u b$ (sentral) elektronik dengan rantai proses tradisional dibidang periklanan $\mathrm{B} 2 \mathrm{~B}$ 


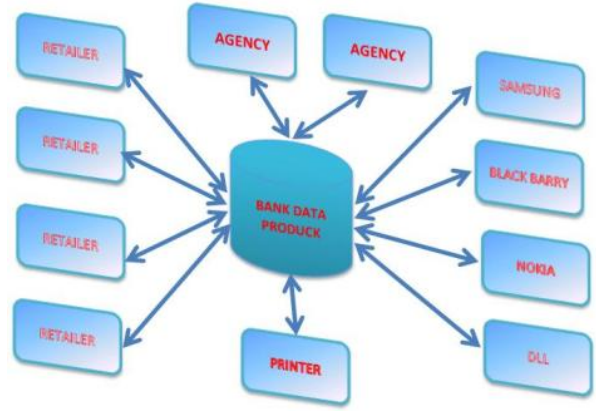

Product Bank data menyederhanakan rantai proses yang panjang menggantikan aliran linear produk dan informasi dengan hub digitasi

\section{Pengujian Modul Pelanggan}

Beberapa Proses yang perlu diuji agar siap digunakan oleh pelanggan antara lain proses validasi login, ubah pelanggan, proses pemesanan dan konfirmasi pembayaran.

\section{Proses Pendaftaran Pelanggan}

Tabel Black Box Pendaftaran Pelanggan

\begin{tabular}{|c|c|c|c|c|}
\hline \multicolumn{2}{|l|}{ Test ID } & \multicolumn{3}{|l|}{ TC- UCP2-02 } \\
\hline \multicolumn{2}{|l|}{ Tujuan Test } & \multicolumn{3}{|c|}{ Melakukan Uji Coba pendaftaran Pelanggan } \\
\hline \multicolumn{2}{|l|}{ Kondisi Awal } & \multicolumn{3}{|c|}{$\begin{array}{l}\text { Menekan tombol pendaftaran pelanggan dan tampil form isian data } \\
\text { pelanggan }\end{array}$} \\
\hline Data Input & Prosedur Pengujian & $\begin{array}{ll}\text { Hasil yang } \\
\text { diharapkan }\end{array}$ & Hasil yang diperoleh & Kesimpulan \\
\hline \multicolumn{5}{|c|}{ Proses Pendaftaran Sukses } \\
\hline $\begin{array}{l}\text { Semua data isian } \\
\text { harus diisi dengan } \\
\text { lengkap tanpa ada } \\
\text { yang kosong }\end{array}$ & $\begin{array}{l}\text { User memilih menu } \\
\text { pendaftaran baru } \\
\text { User mengisi form } \\
\text { yang telah disediakan } \\
\text { User menekan } \\
\text { tombol simpan }\end{array}$ & $\begin{array}{l}\text { Data tersimpan dan } \\
\text { dapat melakukan } \\
\text { login dengan data } \\
\text { yang telah diisi }\end{array}$ & $\begin{array}{l}\text { Data tersimpan dan } \\
\text { dapat melakukan } \\
\text { login dengan data } \\
\text { yang telah diisi }\end{array}$ & $\begin{array}{l}\text { Data harus diisi tanpa } \\
\text { ada isian di form } \\
\text { yang kosong agar } \\
\text { data tersimpan dan } \\
\text { dapat digunakan } \\
\text { untuk melakukan } \\
\text { login }\end{array}$ \\
\hline \multicolumn{5}{|c|}{ Proses Pendaftaran Gagal } \\
\hline $\begin{array}{l}\text { Data diisi dengan } \\
\text { menyisakan beberapa } \\
\text { field di form } \\
\text { pendaftaran kosong }\end{array}$ & $\begin{array}{l}\text { User memilih menu } \\
\text { pendaftaran baru } \\
\text { User mengisi form } \\
\text { yang telah disediakan } \\
\text { dan menyisakan ada } \\
\text { form kosong } \\
\text { User menekan } \\
\text { tombol simpan }\end{array}$ & $\begin{array}{l}\text { Mengeluarkan } \\
\text { kesalahan input }\end{array}$ & $\begin{array}{l}\text { Pendaftaran gagal, } \\
\text { dan mengeluarkan } \\
\text { daftar kesalahan input }\end{array}$ & $\begin{array}{l}\text { Bila ada isian di form } \\
\text { yang kosong data } \\
\text { tidak akan tersimpan } \\
\text { dan tidak dapat } \\
\text { melakukan login }\end{array}$ \\
\hline
\end{tabular}

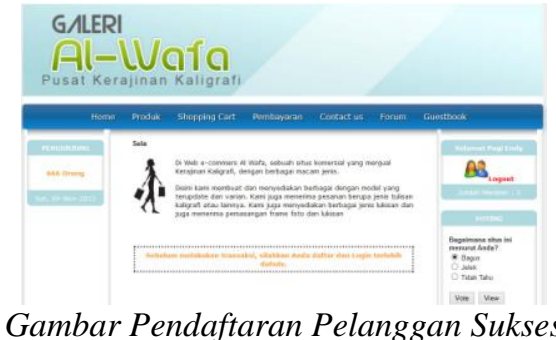

\section{Proses Pemesanan Produk Pelanggan}

Tabel Black Box Pemesanan Produk

\begin{tabular}{|c|c|c|c|c|}
\hline \multicolumn{2}{|c|}{ Test ID } & \multicolumn{3}{|c|}{ TC- UCP2-03 } \\
\hline \multicolumn{2}{|c|}{ Tujuan Test } & \multicolumn{3}{|c|}{ Melakukan Uji Coba Pemesanan Produk Pelanggan } \\
\hline \multicolumn{2}{|c|}{ Kondisi Awal } & $\begin{array}{l}\text { Sistem } \mathrm{m} \\
\text { dapat dipe }\end{array}$ & ampilkan halama & daftar produk yang langsung \\
\hline $\begin{array}{l}\text { Data } \\
\text { Input }\end{array}$ & $\begin{array}{l}\text { Prosedur } \\
\text { Pengujian }\end{array}$ & $\begin{array}{l}\text { Hasil } \\
\text { yang } \\
\text { diharapk } \\
\text { an }\end{array}$ & $\begin{array}{l}\text { Hasil yang } \\
\text { diperoleh }\end{array}$ & Kesimpulan \\
\hline
\end{tabular}




\begin{tabular}{|c|c|c|c|c|}
\hline $\begin{array}{l}\text { User } \\
\text { memilih } \\
\text { produk } \\
\text { yang } \\
\text { akan } \\
\text { dibeli, } \\
\text { dan } \\
\text { memasuk } \\
\text { kan } \\
\text { jumlah } \\
\text { produk } \\
\text { yang } \\
\text { dipesan }\end{array}$ & $\begin{array}{l}\text { User membuka } \\
\text { halaman produk } \\
\text { User melakukan } \\
\text { klik tombol beli } \\
\text { pada produk yang } \\
\text { diinginkan } \\
\text { User } \\
\text { memasukkan } \\
\text { jumlah produk } \\
\text { User menekan } \\
\text { tombol lanjutkan } \\
\text { untuk melengkapi } \\
\text { data man dan } \\
\text { mendapatkan } \\
\text { informasi untuk } \\
\text { pembayaran dan } \\
\text { pengiriman produk }\end{array}$ & $\begin{array}{l}\text { Proses } \\
\text { berhasil } \\
\text { melakuka } \\
\mathrm{n} \\
\text { pemesana } \\
\mathrm{n}, \quad \text { user } \\
\text { dapat } \\
\text { merekam } \\
\text { pemesana } \\
\mathrm{n} \text { produk } \\
\text { yang telah } \\
\text { dilakukan. }\end{array}$ & $\begin{array}{l}\text { Proses berhasil } \\
\text { melakukan } \\
\text { pemesanan, } \\
\text { user dapat } \\
\text { merekam } \\
\text { pemesanan } \\
\text { produk yang } \\
\text { telah dilakukan. }\end{array}$ & $\begin{array}{l}\text { Produk yang dipilih harus } \\
\text { masuk keranjang belanja, dan } \\
\text { User menentukan jumlah } \\
\text { pembelian, agar total biaya } \\
\text { dapat dihitung. }\end{array}$ \\
\hline
\end{tabular}

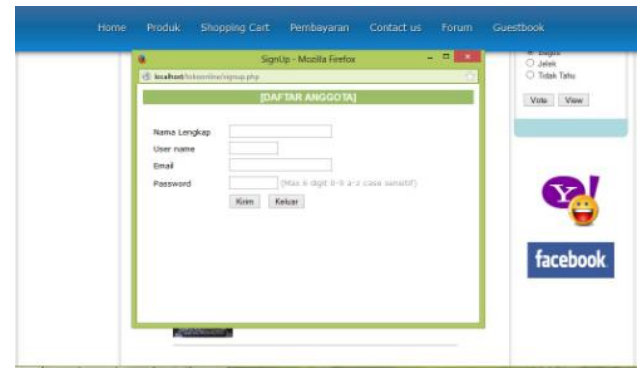

Gambar Form Pendaftaran Pelanggan

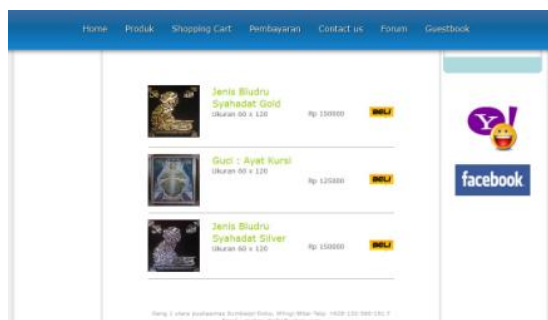

Gambar Pemesanan Produk sukses

Listing Program e-transaksi

Deskripsi : Skrip dibawah berfungsi menyimpan pilihan pelanggan kedalam keranjang belanja berdasarkan kode produk berdasarkan user masing.

$<$ ? session_start();

if (session_is_registered('user_id'))\{

\$iduser $=\$ \_$SESSION['user_id'];

$?>\langle\mathrm{br}>$

$>$ SHOPPING

CART $</$ font $></$ strong $></$ div $></$ td $>$

Tambah Barang $</$ font $><$ img

src="img/produk.jpg" border="0" / $></ \mathrm{a}>\langle$ br $/>$

$\langle\mathrm{br} /\rangle$

include "./include/conn.php";

$\$$ query=mysql_db_query $(\$ \mathrm{db}$, , select * from shoping where iduser='\$iduser' order by

tgl",\$koneksi);

\$pemesanan=mysql_db_query $(\$ \mathrm{db}$, , select

* from pemesanan where iduser='\$iduser' order by

tgl",\$koneksi);

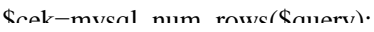

Deskripsi : Skrip dibawah berfungsi memanggil inc.koneksi.php, inc.librari.php, inc.pgl.session.php dan juga menyimpan data transaksi pemesanan. 


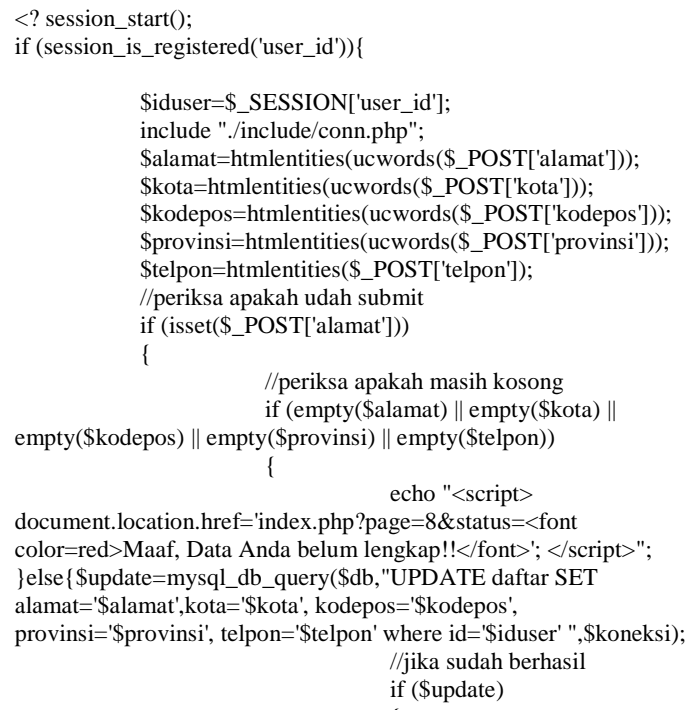

\section{Proses Laporan Pemesanan}

Tabel Black Box Laporan

\begin{tabular}{|c|c|c|c|c|}
\hline \multicolumn{2}{|l|}{ Test ID } & \multicolumn{3}{|l|}{ TC-UCA5-08 } \\
\hline \multicolumn{2}{|l|}{ Tujuan Test } & \multicolumn{3}{|c|}{ Melaporkan data-data yang masuk ke website galeri $\mathrm{Al}$ Wafa } \\
\hline \multicolumn{2}{|c|}{ Kondisi Awal } & \multicolumn{3}{|c|}{ Menu laporan admin } \\
\hline Data Input & Prosedur Pengujian & $\begin{array}{ll}\text { Hasil } & \text { yang } \\
\text { diharapkan }\end{array}$ & Hasil yang diperoleh & Kesimpulan \\
\hline \multicolumn{5}{|c|}{ Proses Laporan Sukses } \\
\hline- & $\begin{array}{l}\text { - User memanggil } \\
\text { halaman laporan } \\
\text { - User memilih } \\
\text { laporan apa yang } \\
\text { akan di lihat }\end{array}$ & Data Laporan Sukses & Data Laporan Sukses & $\begin{array}{l}\text { Laporan di ambil dari } \\
\text { semua data telah } \\
\text { tercatat di database }\end{array}$ \\
\hline
\end{tabular}

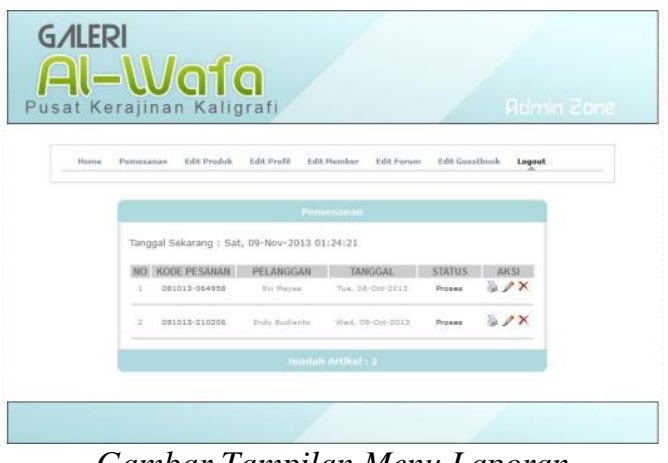

Gambar Tampilan Menu Laporan

\section{Kesimpulan}

1. Sistem informasi UMKM telah selesai dirancang dan dibangun menggunakan PHP dan MySQL dengan pengujian program menggunakan metode Black box, sehingga menghasilkan sistem informasi dengan laporan data berupa data pelanggan dan transaksi. Diharapkan sistem yang telah dibangun dapat memfasilitasi UMKM dan pelanggan untuk dapat memanfaatkan teknologi yang menggunakan mobile computing dalam pengembangan usahanya (UMKM).

2. Dengan sistem ini dapat membantu menyelesaikan masalah yang dihadapi dalam pengembangan UMKM untuk masyarakat dimana yang terjadi saat interaksi antar pengambil keputusan dan pelaksana dalam berbagai tingkat masih perlu penyempurnaan, sehingga sistem ini dalam penggunaannya menjadi efisien dan efektif. 


\section{Daftar Pustaka}

[1]. Abdul Kadir \& Terra Ch. Triwahyuni. (2003). Pengenalan Teknologi Informasi. Andi Offset. Yogyakarta.

[2]. Al Fatta, Hanif. 2007. Analisis dan Perancangan Sistem Informasi. Penerbit Andi, Yogyakarta.

[3]. Davis, B.G. 2001. Kerangka Dasar Sistem Informasi Manajemen. Penerbit pt. Elex Media Komputindo, Jakarta

[4]. Fathansyah, Jr. 1999. Basis Data. Penerbit CV Informatika, Bandung.

[5]. FN Jovan 2007. Panduan Praktis Membuat Web dengan PHP. Penerbit Media Kita.

[6]. HM, Jogiyanto. 2001. Analisis dan Desain Sistem Informasi. Penerbit ANDI, Yogyakarta.

[7]. Hoffer, Jeffrey, A, et all. (2002). Modern Database management. New Jersey : Pearson Edecation, Inc.

[8]. Joel Spolsky. (2001). User interface design for programmer. Hongkong : C \& C Offset Printing Co., Ltd.

[9]. Kadir, Abdul. 2003. Pemrograman Web. Penerbit Andi, Yogyakarta

[10]. Mc Leod. 1995. Sistem Informasi Manajemen Jilid I. Penerbit PT Prenhallindo, Jakarta.

[11]. Miles, M.B., \& Hubermant, A.M. (1992). Qualitatif data analysis. (Terjemahan Tjetjep Rohendi Rohidi). London : Sage Publishing.

[12]. Moleong, Lexy.J. (1989). Metodologi Penelitian kualitatif. Bandung : P.T. Rosda Karya.

[13]. Nogroho, Bunafit. 2008. Sistem Informasi Berbasis Web dengan PHP dan MySQL. Penerbit Gava Media, Jakarta. 